\title{
EDITORIAL
}

\section{Translational research is all-encompassing and lets everyone be}

\section{a researcher}

\author{
Pediatric Research (2021) 90:2-3; https://doi.org/10.1038/s41390- \\ 020-01225-4
}

\section{TRANSLATIONAL RESEARCH}

Biomedical research can be categorized based on its aim: (1) to determine the underlying nature of things (basic research) and (2) to understand the underlying nature of things in order to be able to improve human health (translational research). There are a diverse number of definitions of translational research, which usually includes an all-encompassing overview of all biomedical research from basic translational science to clinical implementation. ${ }^{1}$ The National Center for Advancing Translational Sciences (NCATS') definition of translation is broad and inclusive: "translation is the process of turning observations in the laboratory, clinic and community into interventions that improve the health of individuals and the public-from diagnostics and therapeutics to medical procedures and behavioural changes." ${ }^{1}$ This definition technically applies to much of the research in biomedical sciences ranging from preliminary laboratory-based research to epidemiology and implementation science. The core message is that research with the aim of improving health can ultimately be translated from the bench to patient care. ${ }^{2}$ We therefore realized in Pediatric Research that defining a subset of articles as a category termed translational research was incorrect and removed this term. Instead, all articles published in Pediatric Research represent translational research and categorized based on methodology: basic translational research, clinical translational research, or population translational research, with translational research as the overriding theme of the journal (Fig. 1).

\section{EVERYONE IS A RESEARCHER}

There is a huge value for all healthcare personnel and families to participate in research. Although career development is another important motivation, the advantages are the ability to cope with rejection and there is increasing evidence that being research-active avoids burnout and builds resilience. ${ }^{3,4}$ It is postulated that research develops a deep sense of purpose of oneself and allows one the chance to change and improve outcomes. Everyone can be involved in research, either in their daily clinical practice including quality improvement or to laboratory-based or epidemiologic research. Translational research from basic to epidemiologic has been the basis of the seven great advances in pediatrics, including: immunizations to prevent disease, reducing sudden infant death, cure for acute lymphoblastic leukemia, surfactant therapy for premature infants, preventing vertical HIV transmission, improving life expectancy for children with sickle cell anemia and cystic fibrosis, and saving lives with car seats and seat belts. $^{5}$
Cheng et al. ${ }^{6}$ have also suggested that the future of pediatric research advancements, including new immunizations, cancer immunotherapy, genomics discoveries, identification of early antecedents of adult health, impact of specific social-environmental influences on biology and health, quality improvement science, and implementation and dissemination research to reduce global poverty, would be based on translational research. Further research and programmatic investment early in the life course is essential.

\section{CHILDREN AND FAMILY INVOLVEMENT IN RESEARCH}

There are many motivations for families to participate in research. Healthcare workers are predominantly altruistic to get evidence-based answers for clinical applications that can improve outcomes for children and families. ${ }^{7}$ Patients' and public involvement (PPI) is a way of involving anyone not professionally interested or experienced in health care into research. The engagement of patients and the public into research is termed participatory research.

Upholding the rights of the child enshrined in the United Nation's Convention on the Rights of the Child (UN CRC), which states that all children have the right to an opinion and to express their views. They all should have the right to be informed and give their opinion about the world around them. ${ }^{8}$

Developing PPI using resources, such as medical conferences, publishing, editorial, and research boards, are vital. The James Lind alliance is an organization with the idea of bringing together clinicians, patients, and carers to discuss research priorities and to develop the top 10 research priorities (http://www.jla.nihr.ac.uk/). Initiatives for children to lead research projects have been developed. This research projects also increase awareness about the benefits of research and clinical trials. Child-led research has several prominent examples including RCTS by children (https:// www.hrb-tmrn.ie/public-engagement/start-competition/) to develop better quality evidence, and more applicable and impactful research. In these PPI, children are involved in all aspects of the project from its inception to publication and implementation and are a source of empowerment.

\section{DEVELOPING RESEARCH CAPACITY}

In Pediatric Research, we have started a series of editorials on career development at all stages from early career investigator to senior roles. Training for research is vital. National and international resources are available. For example, in the UK the academic toolkit (https://academictoolkit.org/) has been developed in conjunction with the Royal College of Pediatrics and Child Health $(\mathrm{RCPCH})$ for pediatricians in training. There are multiple resources for families and patients who want to be involved in PPI, including training courses (http://www.icphr.org/ppiphr-courses.html) and the RCPCH patient research charter. ${ }^{9}$ Improvement in research infrastructure and training were noted by the $\mathrm{RCPCH}$ in their document "Turning the Tide 5 years on," but they noted more 


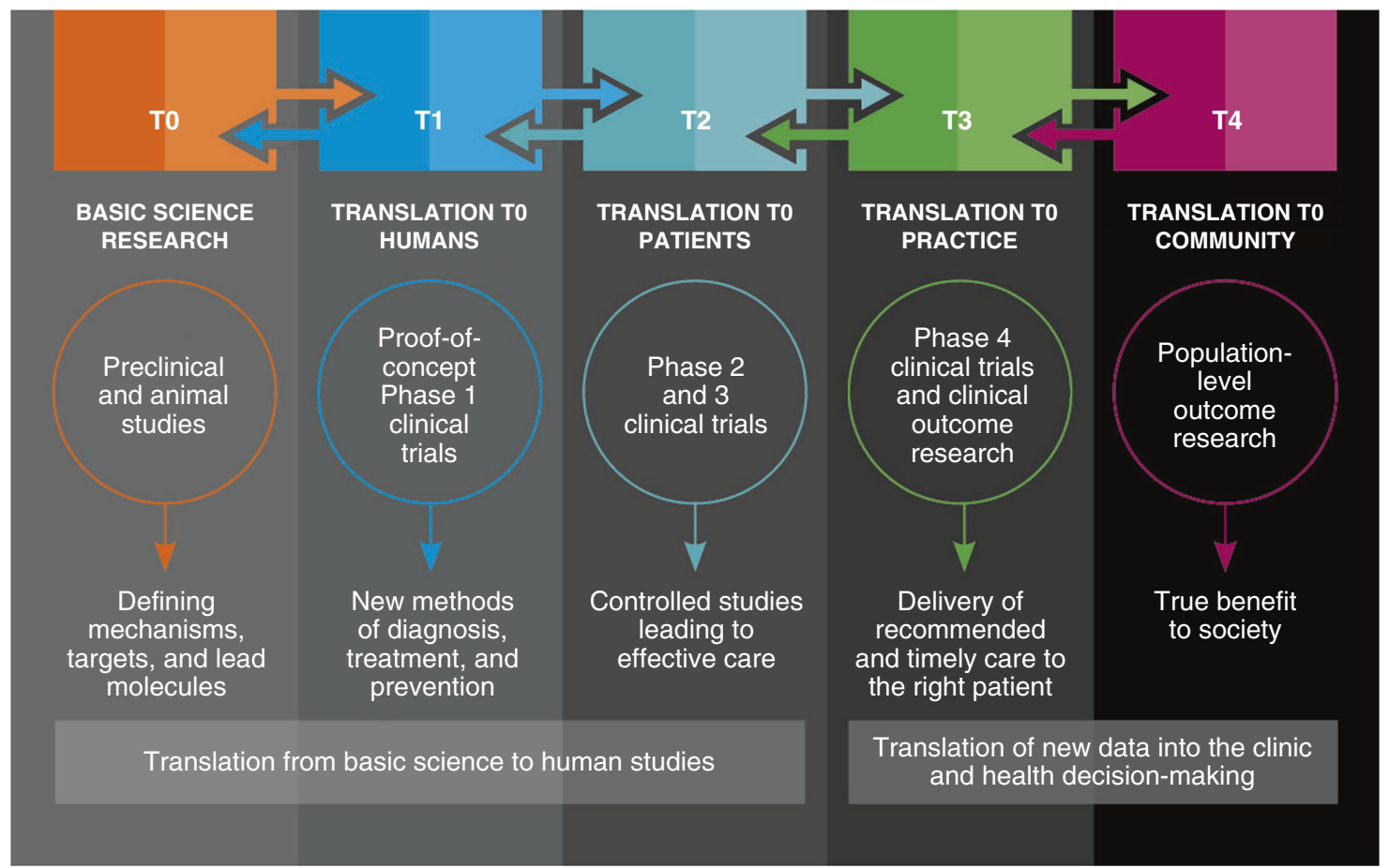

Fig. 1 Translational research paradigm. Adapted from image by Macmillan Publishers Ltd. Nature Medicine (Blumberg et al., copyright 2012).

development was needed (Turing the Tide 5 years on... https:// www.rcpch.ac.uk/sites/default/files/2018-03/turning_the_tide__five_years_on_2018-03.pdf).

Database development, artificial intelligence, and big data will be major resources when combined with new discovery and human capacity in research. The concept that all healthcare professionals are researchers helps to ensure the integration of research in health care. Healthcare professionals have a privileged position to improve family outcomes through translational research and the engagement of all stakeholders.

\section{ACKNOWLEDGEMENTS}

This work was supported by National Children's Research Centre, Crumlin, Dublin, Ireland and Health Research Board Ireland (to E.J.M.) and NIH/NICHD P01HD085928 (to C.F.B.).

\section{AUTHOR CONTRIBUTIONS}

E.J.M. and C.F.B.: substantial contributions to conception and design, revising the article critically for important intellectual content; final approval of the version to be published.

\section{ADDITIONAL INFORMATION}

Competing interests: The authors declare no competing interests.

Publisher's note Springer Nature remains neutral with regard to jurisdictional claims in published maps and institutional affiliations.
Eleanor J. Molloy ${ }^{1,2,3,4,5}$ and Cynthia F. Bearer ${ }^{6,7}$ ${ }^{1}$ Discipline of Paediatrics, Trinity College, The University of Dublin, Dublin, Ireland; ${ }^{2}$ Children's Health Hospital (CHI) at Tallaght, Tallaght University Hospital, Dublin, Ireland; ${ }^{3}$ Trinity Translational Medicine Institute (TTMI), St. James Hospital and Trinity Research in Childhood Centre (TriCC), Dublin, Ireland; ${ }^{4}$ Department of Neonatology, CHI at Crumlin, Dublin, Ireland; ${ }^{5}$ Department of Paediatrics, Coombe Women's and Infant's University Hospital, Dublin, Ireland; ${ }^{6}$ Department of Pediatrics, Division of Neonatology, Rainbow Babies and Children's Hospital, Cleveland, $\mathrm{OH}, \mathrm{USA}$ and ${ }^{7}$ Case Western Reserve University School of Medicine, Cleveland, $\mathrm{OH}$, USA Correspondence: Eleanor J. Molloy (eleanor.molloy@tcd.ie)

\section{REFERENCES}

1. Austin, C. P. Translation translation. Nat. Rev. Drug Discov. 17, 455-456 (2018).

2. Rubio, D. M. et al. Defining translational research: implications for training. Acad. Med. 85, 470-475 (2010).

3. Halliday, L., Walker, A., Vig, S., Hines, J. \& Brecknell, J. Grit and burnout in UK doctors: a cross-sectional study across specialties and stages of training. Postgrad. Med. J. 93, 389-394 (2017).

4. Galaiya, R., Kinross, J. \& Arulampalam, T. Factors associated with burnout syndrome in surgeons: a systematic review. Ann. R. Coll. Surg. Engl. 102, 401-407 (2020).

5. Cheng, T. L., Bogue, C. W. \& Dover, G. J. The next 7 great achievements in Pediatric Research. Pediatrics 139, e20163803 (2017).

6. Cheng, T. L. et al. Seven great achievements in pediatric research in the past $40 \mathrm{y}$. Pediatr. Res. 80, 330-337 (2016). pmid:27556199.

7. Molloy, E. J., Mader, S., Modi, N. \& Gale, C. Parent, child and public involvement in child health research: core value not just an optional extra. Pediatr. Res. 85, 2-3 (2019).

8. Molloy, E. J. Dr Janusz Korczak: paediatrician, children's advocate and hero. Pediatr. Res. 86, 783-784 (2019).

9. Hunter, L. et al. Advancing child health research in the UK: the Royal College of Paediatrics and Child Health Infants' Children's and Young People's Research Charter. Arch. Dis. Child. 102, 299-300 (2017). 